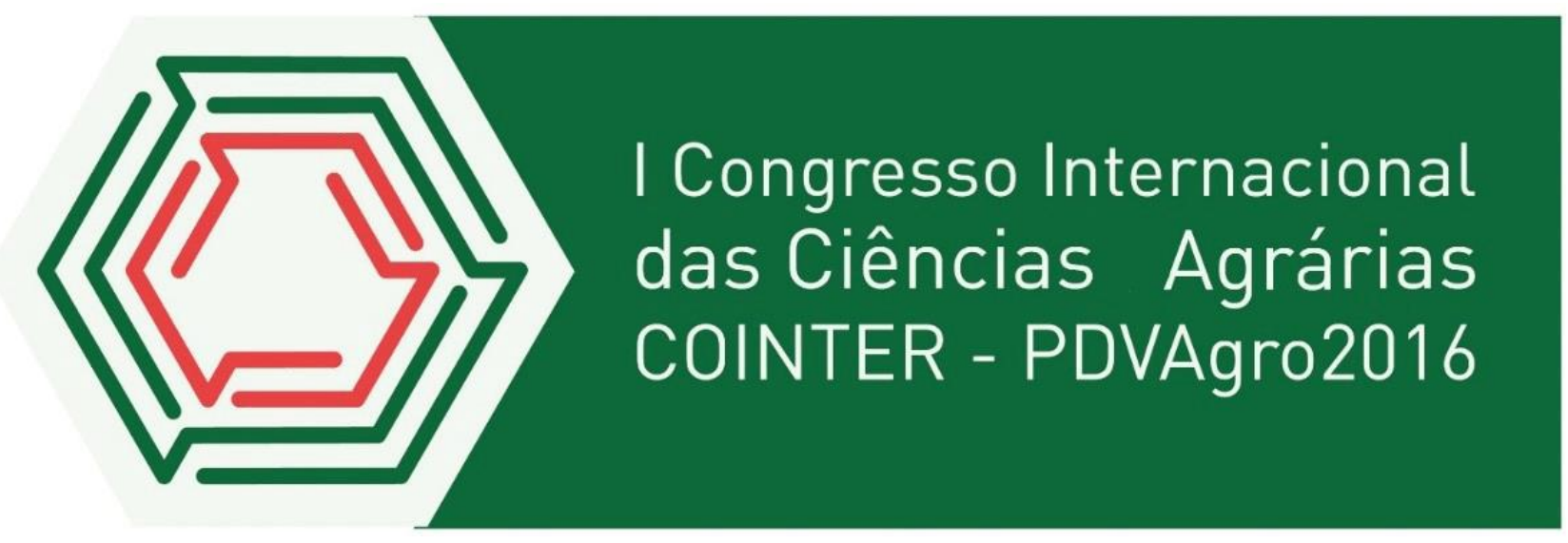

\title{
AVALIAÇÃO ESTRUTUTURAL DE UMA COMUNIDADE RURAL DE PRODUÇÃO AGRÍCOLA ORGÂNICA SOB A PERSPECTIVA DO ISOMORFISMO MIMÉTICO.
}

\author{
Apresentação: Relato de Experiência \\ Mateus Valdevino de Siqueira ${ }^{1}$; Anelise Martins de Azevedo ${ }^{2}$; Aucidezio Sales da Silva ${ }^{3}$, \\ Gerciana Maria Freire ${ }^{4}$, Erick Viana da Silva ${ }^{5}$.
}

\section{Introdução}

O presente trabalho relata uma atividade do Programa Internacional Despertando Vocações Para Ciências Agrárias com a participação de estudantes de engenharia civil, gestão em turismo e agronomia com vistas a avaliação das condições estruturais da comunidade de Marrecos, localizada no município de Lagoa do Itaenga-PE, para implantação de um projeto de turismo pedagógico. A teoria institucional, especificamente os trabalhos de Di Maggio e Powell, aponta na direção de que as organizações com a finalidade de sobreviver em seu ambiente e se perpetuarem tendem ao longo do tempo a tomarem formas idênticas, ou isomórficas. Dentre os isomorfismos citados, o presente trabalho identificou na análise feita pelos estudantes uma tendência natural em aproveitar os recursos naturais presentes no local e adequá-los à exemplos exitosos ocorridos em outros espaços. Dessa forma percebeu-se através da visita de extensão, ocorrida no mês de outubro de 2016, acompanhada por uma moradora local, a capacidade de produção agrícola orgânica dessa comunidade como atrativo turístico pedagógico e do potencial de tornar a comunidade um produto turístico que possa trazer renda aos seus membros.

Com o auxílio de geoprocessamento para formação de esboço das propriedades foram analisadas variáveis como a infraestrutura local responsável por atender tal demanda baseada no isomorfismo, e recursos naturais disponíveis, sendo levantado um relato sobre as possíveis melhorias que a

\footnotetext{
${ }^{1}$ Engenharia Civil, Instituto Federal de Pernambuco, mateusengh@gmail.com

2 Engenharia Civil, Instituto Federal de Pernambuco, liziemartins@gmail.com

${ }^{3}$ Gestão de Turismo, Instituto Federal de Pernambuco, audezio@gmail.com

${ }^{4}$ Gestão de Turismo, Instituto Federal de Pernambuco, gercianamaria@gmail.com

${ }^{5}$ Mestre, Instituto Federal de Pernambuco, erickviana@recife.ifpe.edu.br
} 
comunidade pode obter a curto e médio prazo através de tais ações, interligando áreas de conhecimento como: administração, engenharia e agricultura.

\section{Relato de Experiência}

A visita de extensão a comunidade de Marrecos teve por objetivo a análise das condições de turismo pedagógico no local, tendo como atrativo principal a produção de alimentos de base orgânica. Verificou-se como principais problemas a ausência de recursos financeiros, além da limitação do recurso natural água, este de significativa importância para o desenvolvimento da agricultura orgânica. A metodologia se baseou em levantamento topográfico com auxílio de GPS para realização do croqui da área de atuação, registro fotográfico e informações informais com moradores locais.

Constatamos que os produtos comercializados são de origem orgânica devido à cultura rural do local e um elemento de resistência pode ser encontrado pela influência das gerações mais antigas, que possui seu processo produtivo modulado através de crenças e ritos que não estão ligados a realidade turística, conforme se pode observar a teoria institucional (CLEGG, S. R. et al, 1999). A produção agrícola orgânica é, devido à incerteza da produção, copiada de produções anteriores sem elementos técnicos de planejamento, tomam-se como referenciais produções orgânicas anteriores obtidas com sucesso, fazendo com que os demais agricultores reproduzam o mesmo processo (DiMaggio e Powell, 1983). A infraestrutura local é precária, não há sistema de captação de água, determinação física de áreas de plantio e sinalização das propriedades.

\section{Considerações}

Por fim, conclui-se que a comunidade de Marrecos possui potencial de produção agrícola capaz de beneficiar a si através de turismo pedagógico, entretanto necessita de ajustes prévios que irão ser base para tal. Ajuste estes como melhoria da sua infraestrutura, possível reuso de águas cinza para auxílio no plantio e/ou reuso de águas pluviais. Devido ao custo desse investimento, ainda assim baixo, busca-se parcerias com ONG's e palestras para difusão de conhecimento proporcionada por institutos e universidades.

\section{Referências}

CLEGG, S. R. et al. Handbook de Estudos Organizacionais: Modelos de Análise e Novas Questões em Estudos Organizacionais. In: Atlas, Brasil: 1999. p. 196-213.

DIMAGgIO, P. J.; POWELL, W.W. The Iron Cage Revisited: Institutional Isomorphism and Collective Rationality in Organizational Fields. American Sociological Review, v. 48, n. 2, 1983. p. 147-160. 